\title{
Hybrid Active Power Filter: Design Criteria
}

\author{
S. P. Litrán, P. Salmerón, R.S. Herrera \\ Departamento de Ingeniería Eléctrica y Térmica \\ Escuela Politécnica Superior, Universidad de Huelva \\ Ctra. de Palos de la Frontera s/n, 21819, Palos de la Frontera, Huelva, Spain \\ Phone: +34-959217585, Fax: +34-959217304 \\ e-mail: salvador@uhu.es; patricio@uhu.es; reyes.sanchez@die.uhu.es
}

\begin{abstract}
The configuration of a series active power filter (APF) and a parallel passive filter (PPF) has proven to be an efficient system for nonlinear load compensation. For this topology, different compensation strategies have been proposed to control the series APF. The most effective strategy determines the APF refrerence voltage as a proportion of the source current harmonics. The proportionality constant in the control algorithm implementation is related to the APF gain and the system dynamics. In this paper, the system state model has been obtained for three control strategies of series APF: voltage proportional to source current harmonics, voltage opposite to the load voltage harmonics and a hybrid strategy which combines both previous. The resulting model analyses provide the information needed to establish design criteria for each strategy, both in terms of harmonic filtering and the system stability. The three strategies were compared in two different situations: sinusoidal supply voltages and distorted supply voltages. Finally, results of an experimental prototype developed for this purpose allowed the proposed analysis to be verified.
\end{abstract}

\section{Key words}

Power quality, active filters, hybrid filters, harmonics, state model.

\section{Introduction}

Active power filters (APF) have shown to be an effective technology to eliminate harmonics and to compensate nonlinear loads [1-3]. The shunt connection has been the most studied topology, where the APF is connected in parallel with the load. One of its traditional uses is the elimination of current harmonics produced by loads which generates such disturbances, this is HCS loads (Harmonic Current Source) [4,5]. However, the parallel APF is not suitable in situations where the load generates voltage harmonics, HVS loads (Harmonic Voltage Source). In this case, series connection APF configuration has been proposed and different control strategies have been tried out [6].
Compensation systems composed only of an APF either shunt or series connection do not solve completely the problem of harmonic elimination for all load types. So, other configurations have been proposed [1]. They combine series and parallel topologies, active and passive filters.

Among the hybrid topologies, the series APF with parallel passive filter (SAPPF) is the most studied. Specifically for this configuration, different control strategies have been proposed. One of them has its origin in the early $90 \mathrm{~s}$; the control objective was based on generating a voltage proportional to the source current harmonics. This APF control strategy allowed to improve the filtering features of parallel connection passive filter [7]. The functionality of the new strategy is analyzed from a steady state model; however, this theoretical development is not suitable to study the system stability or to determine the proportionality constant value.

Subsequently, other control strategies for the series APF appeared. Thus, in [8-10] three control strategies are analyzed

In this paper the theoretical analysis of a hybrid filter constituted by a series APF and shunt passive filter is carried out. For this, the state model equations are obtained from its single phase equivalent circuit. The behaviour of compensating equipment is analyzed for three different control strategies:

- Source current detection (SCD). In this strategy, the filter generates a voltage proportional to the source current harmonics.

- Load voltage detection (LVD). In this strategy the active filter generates a voltage opposite to the load voltage harmonics.

- Current and voltage detection (CVD). This strategy combines the source current detection and the load voltage detection. 
The resulting model allows to stablish the control specifications to ensure system stability and to eliminate the source current harmonics. For this purpose a simulation platform based on MATLAB-Simulink has been developed. Each strategy is analyzed in the cases of sinusoidal supply voltage and nonsinusoidal supply voltage.

Finally, a SAPPF experimental prototype has been developed. The three compensating strategies have been applied to the series APF, which has allowed the theoretical analysis to be contrasted.

\section{State Model of Hybrid Active Power Filter}

Fig. 1 shows a three-phase circuit with a voltage source that feeds a HCS type nonlinear load and a SAPPF hybrid filter. The source impedance is constituted by a resistance $\mathrm{R}_{\mathrm{S}}$ and an inductance $\mathrm{L}_{\mathrm{S}}$. The active power filter is connected in series with the source through a coupling transformer. The passive filter is connected in parallel with the load. It consists of two LC branches tuned to $5^{\text {th }}$ and $7^{\text {th }}$ current harmonics.

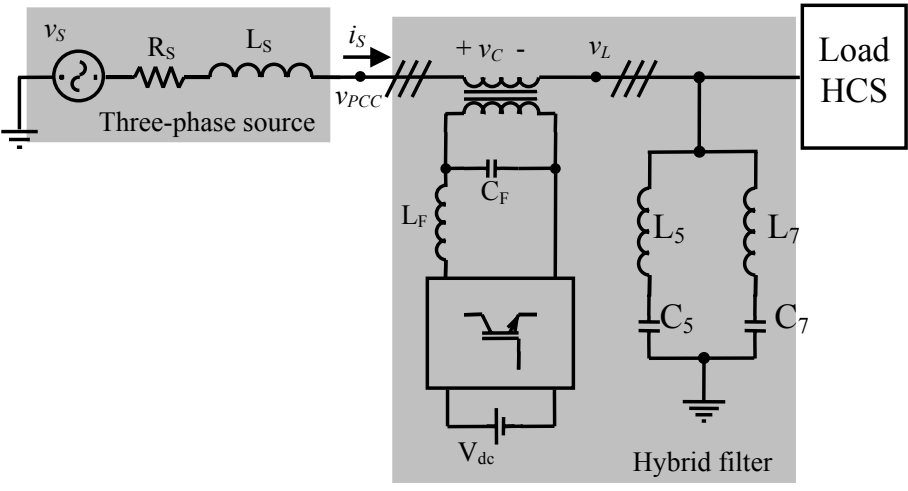

Fig. 2. System with SAPPF filter and load type HCS

The circuit used to obtain the system state model is shown in Fig. 2. This circuit represents the equivalent singlephase network of Fig. 1 for any h order harmonic different of the fundamental harmonic. The active filter is modeled by a controlled voltage source, $u$. As load model the Norton equivalent has been used, defined by a resistor, $\mathrm{R}_{\mathrm{L}}$, in parallel with an inductance, $\mathrm{L}_{\mathrm{L}}$, and a current source $i_{L}$. This current source will be zero for the fundamental harmonic. The passive filter consists of two LC branches tuned to the harmonics of interest. Each LC branch includes a resistance which models the resistive effect which is mainly present in the reactors.

Considering the circuit in Fig. 2, the definition of the next is possible state equation is possible

$$
\begin{aligned}
& \dot{\mathbf{x}}=\mathbf{A} \mathbf{x}+\mathbf{B}_{1} \mathbf{u}+\mathbf{B}_{2} \mathbf{v} \\
& \mathbf{y}=\mathbf{C} \mathbf{x}+\mathbf{D}_{1} \mathbf{u}+\mathbf{D}_{2} \mathbf{v}
\end{aligned}
$$

Where $\mathbf{x}$ is the state vector whose components are the state variables, $\mathbf{u}$ is the control variable, $\mathbf{v}$ the input vector and $\mathbf{y}$ the system output.

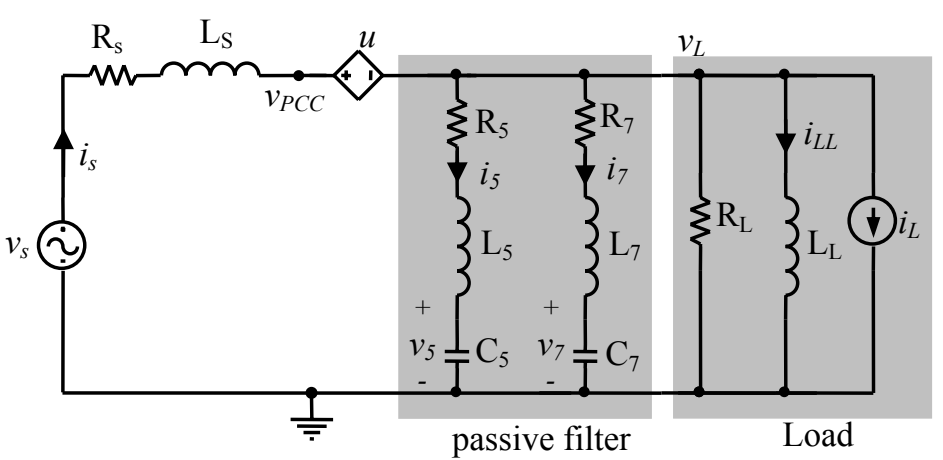

Fig. 1. Equivalent single phase circuit of the system of the Fig. 2

Where $\mathbf{x}$ is the state vector whose components are the state variables, $\mathbf{u}$ is the control variable, $\mathbf{v}$ the input vector and $\mathbf{y}$ the system output.

For the variables defined in Fig. 2 circuit, the state vector is composed of the currents through the inductances and the capacitors voltages

$$
\mathbf{x}=\left[\begin{array}{llllll}
i_{S} & i_{5} & i_{7} & i_{L L} & v_{5} & v_{7}
\end{array}\right]^{T}
$$

The system matrix is given by

$$
\mathbf{A}=\left[\begin{array}{cccccc}
-\frac{\left(R_{S}+R_{L}\right)}{L_{S}} & \frac{R_{L}}{L_{S}} & \frac{R_{L}}{L_{S}} & \frac{R_{L}}{L_{S}} & 0 & 0 \\
\frac{R_{L}}{L_{5}} & -\frac{\left(R_{L}+R_{5}\right)}{L_{5}} & -\frac{R_{L}}{L_{5}} & -\frac{R_{L}}{L_{5}} & -\frac{1}{L_{5}} & 0 \\
\frac{R_{L}}{L_{7}} & -\frac{R_{L}}{L_{7}} & -\frac{\left(R_{L}+R_{7}\right)}{L_{7}} & -\frac{R_{L}}{L_{7}} & 0 & -\frac{1}{L_{7}} \\
\frac{R_{L}}{L_{L}} & -\frac{R_{L}}{L_{L}} & -\frac{R_{L}}{L_{L}} & -\frac{R_{L}}{L_{L}} & 0 & 0 \\
0 & \frac{1}{C_{5}} & 0 & 0 & 0 & 0 \\
0 & 0 & \frac{1}{C_{7}} & 0 & 0 & 0
\end{array}\right]
$$

In this case the $\mathbf{B}_{\mathbf{1}}$ vector has the form

$$
\mathbf{B}_{1}=\left[\begin{array}{llllll}
-\frac{1}{L_{S}} & 0 & 0 & 0 & 0 & 0
\end{array}\right]^{T}
$$

$\mathbf{B}_{\mathbf{2}}$ is defined by the matrix

$$
\mathbf{B}_{2}=\left[\begin{array}{cccccc}
\frac{1}{L_{S}} & 0 & 0 & 0 & 0 & 0 \\
\frac{R_{L}}{L_{S}} & -\frac{R_{L}}{L_{5}} & -\frac{R_{L}}{L_{7}} & -\frac{R_{L}}{L_{L}} & 0 & 0
\end{array}\right]^{T}
$$

And the input vector takes the form

$$
\mathbf{v}=\left[\begin{array}{ll}
v_{S} & i_{L}
\end{array}\right]^{T}
$$

The matrices $\mathbf{C}, \mathbf{D}_{\mathbf{1}}$ and $\mathbf{D}_{\mathbf{2}}$ depend on the selected output. If the source current $\left(i_{S}\right)$ is taken as an output signal, the matrices are as follows

$$
\mathbf{C}=\left[\begin{array}{llllll}
1 & 0 & 0 & 0 & 0 & 0
\end{array}\right]
$$




$$
\mathbf{D}_{1}=\mathbf{D}_{2}=[0]
$$

\section{Analysis of Different Compensation Strategies}

In this section the state equations corresponding to the strategies SCD, LVD and CVD are obtained. The different developments allow the influence of each control strategy on the system matrix to be analyzed.

\section{A. Control strategy of source current detection}

When the control strategy proportional to the source current harmonics is applied, the voltage generated by the $\mathrm{APF}$ is given by the expression

$$
u=k i_{S}
$$

Where $k$ is the proportionality constant. In matrix form, it can be expressed as

$$
\mathbf{u}=\left[\begin{array}{llllll}
k & 0 & 0 & 0 & 0 & 0
\end{array}\right]\left[\begin{array}{llllll}
i_{S} & i_{5} & i_{7} & i_{L L} & v_{5} & v_{7}
\end{array}\right]^{T}(10)
$$

Therefore, this strategy is based on the feedback of the state vector through a gain matrix, $\mathbf{K}$, which is defined by the expression

$$
\mathbf{K}=\left[\begin{array}{llllll}
k & 0 & 0 & 0 & 0 & 0
\end{array}\right]
$$

With this control strategy, the state equation (1) can be expressed as

$$
\dot{\mathbf{x}}=\left(\mathbf{A}+\mathbf{B}_{1} \mathbf{K}\right) \mathbf{x}+\mathbf{B}_{2} \mathbf{v}
$$

Where the system matrix is defined by

$$
\begin{aligned}
& \mathbf{A}^{\prime}=\left(\mathbf{A}+\mathbf{B}_{1} \mathbf{K}\right)= \\
& =\left[\begin{array}{cccccc}
-\frac{\left(R_{S}+R_{L}+k\right)}{L_{S}} & \frac{R_{L}}{L_{S}} & \frac{R_{L}}{L_{S}} & \frac{R_{L}}{L_{S}} & 0 & 0 \\
\frac{R_{L}}{L_{5}} & -\frac{\left(R_{L}+R_{5}\right)}{L_{5}} & -\frac{R_{L}}{L_{5}} & -\frac{R_{L}}{L_{5}} & -\frac{1}{L_{5}} & 0 \\
\frac{R_{L}}{L_{7}} & -\frac{R_{L}}{L_{7}} & -\frac{\left(R_{L}+R_{7}\right)}{L_{7}} & -\frac{R_{L}}{L_{7}} & 0 & -\frac{1}{L_{7}} \\
\frac{R_{L}}{L_{L}} & -\frac{R_{L}}{L_{L}} & -\frac{R_{L}}{L_{L}} & -\frac{R_{L}}{L_{L}} & 0 & 0 \\
0 & \frac{1}{C_{5}} & 0 & 0 & 0 & 0 \\
0 & 0 & \frac{1}{C_{7}} & 0 & 0 & 0
\end{array}\right]
\end{aligned}
$$

By comparing (3) and (13), only the first term of the $\mathbf{A}^{\prime}$ matrix is different from the A matrix with this strategy.

\section{B. Control strategy of load voltage detection}

In this control strategy the voltage generated by the active filter is given by the expression

$$
u=-k_{v} v_{L}
$$

Where $k_{v}$ models the instrumentation sensitivity and $v_{L}$ is the voltage at the load side. In Fig. 2 circuit, the voltage $v_{L}$ gets the next expression

$$
v_{L}=R_{L} i_{S}-R_{L} i_{5}-R_{L} i_{7}-R_{L} i_{L L}-R_{L} i_{L}
$$

According to (14) and (15) the control signal can be expressed by

$$
u=-k_{v} R_{L} i_{S}+k_{v} R_{L} i_{5}+k_{v} R_{L} i_{7}+k_{v} R_{L} i_{L L}+k_{v} R_{L} i_{L}
$$

Thus, the system input vector is given by

$$
\mathbf{u}=\mathbf{K}_{1} \mathbf{x}+\mathbf{K}_{2} \mathbf{v}
$$

Where

$$
\mathbf{K}_{1}=\left[\begin{array}{llllll}
-k_{v} R_{L} & k_{v} R_{L} & k_{v} R_{L} & k_{v} R_{L} & 0 & 0
\end{array}\right]
$$

And

$$
\mathbf{K}_{2}=\left[\begin{array}{ll}
0 & k_{v} R_{L}
\end{array}\right]
$$

Finally, the state equation can be written as follows

$$
\dot{\mathbf{x}}=\left(\mathbf{A}+\mathbf{B}_{\mathbf{1}} \mathbf{K}_{1}\right) \mathbf{x}+\left(\mathbf{B}_{\mathbf{2}}+\mathbf{B}_{\mathbf{1}} \mathbf{K}_{2}\right) \mathbf{v}
$$

Now, the system matrix is

$\mathbf{A}^{\prime}=\left(\mathbf{A}+\mathbf{B}_{1} \mathbf{K}_{1}\right)=$

$$
=\left[\begin{array}{ccccccc}
-\frac{\left(R_{S}+R_{L}\left(1-k_{v}\right)\right)}{L_{S}} & \frac{R_{L}\left(1-k_{v}\right)}{L_{S}} & \frac{R_{L}\left(1-k_{v}\right)}{L_{S}} & \frac{R_{L}\left(1-k_{v}\right)}{L_{S}} & 0 & 0 \\
\frac{R_{L}}{L_{5}} & -\frac{\left(R_{L}+R_{5}\right)}{L_{5}} & -\frac{R_{L}}{L_{5}} & -\frac{R_{L}}{L_{5}} & -\frac{1}{L_{5}} & 0 \\
\frac{R_{L}}{L_{7}} & -\frac{R_{L}}{L_{7}} & -\frac{\left(R_{L}+R_{7}\right)}{L_{7}} & -\frac{R_{L}}{L_{7}} & 0 & -\frac{1}{L_{7}} \\
\frac{R_{L}}{L_{L}} & -\frac{R_{L}}{L_{L}} & -\frac{R_{L}}{L_{L}} & -\frac{R_{L}}{L_{L}} & 0 & 0 \\
0 & \frac{1}{C_{5}} & 0 & 0 & 0 & 0 \\
0 & 0 & \frac{1}{C_{7}} & 0 & 0 & 0
\end{array}\right]
$$

This strategy modifies the first row of the system matrix and the matrix that multiplies the input vector.

C. Control strategy of current and voltage detection With the hybrid strategy, the active filter must generate a voltage waveform defined by means of

$$
u=k i_{S}-k_{v} v_{L}
$$

According to Fig. 2 circuit, the control signal can be calculated by

$$
u=\left(k-k_{v} R_{L}\right) i_{S}+k_{v} R_{L} i_{5}+k_{v} R_{L} i_{7}+k_{v} R_{L} i_{L L}+k_{v} R_{L} i_{L}
$$

Which is expressed in matrix form as follows

$$
\mathbf{u}=\mathbf{K}_{1} \mathbf{x}+\mathbf{K}_{2} \mathbf{v}
$$

Where

$$
\begin{gathered}
\mathbf{K}_{\mathbf{1}}=\left[\begin{array}{cccccc}
\left(k-k_{v} R_{L}\right) & k_{v} R_{L} & k_{v} R_{L} & k_{v} R_{L} & 0 & 0
\end{array}\right] \\
\mathbf{K}_{\mathbf{2}}=\left[\begin{array}{lll}
0 & k_{v} R_{L}
\end{array}\right]
\end{gathered}
$$

So, the state equation is defined by

$$
\dot{\mathbf{x}}=\left(\mathbf{A}+\mathbf{B}_{1} \mathbf{K}_{1}\right) \mathbf{x}+\left(\mathbf{B}_{2}+\mathbf{B}_{1} \mathbf{K}_{2}\right) \mathbf{v}
$$

Here the system matrix is as follows 
$\mathbf{A}^{\prime}=\left(\mathbf{A}+\mathbf{B}_{1} \mathbf{K}_{\mathbf{1}}\right)=$

$=\left[\begin{array}{c}-\frac{\left(R_{S}+R_{L}\left(1-k_{v}\right)+k\right)}{L_{S}} \\ \frac{R_{L}}{L_{5}} \\ \frac{R_{L}}{L_{7}} \\ \frac{R_{L}}{L_{L}} \\ 0 \\ 0\end{array}\right.$

$\left.\begin{array}{ccc}\frac{R_{L}\left(1-k_{v}\right)}{L_{S}} & 0 & 0 \\ -\frac{R_{L}}{L_{5}} & -\frac{1}{L_{5}} & 0 \\ -\frac{R_{L}}{L_{7}} & 0 & -\frac{1}{L_{7}} \\ -\frac{R_{L}}{L_{L}} & 0 & 0 \\ 0 & 0 & 0 \\ 0 & 0 & 0\end{array}\right]$

(28)

The CVD control strategy modifies the first row of the matrix and the matrix system that multiplies the input vector.

\section{Experimental Results}

An experimental prototype of the circuit shown in Fig. 1 has been implemented. The system is supplied by a programmable three-phase source, the California Instruments $4500-\mathrm{iL}$ model. The source impedance is constituted by a resistor, $\mathrm{R}_{\mathrm{S}}=1.8 \Omega$ and an inductance, $\mathrm{L}_{\mathrm{S}}=2.8 \mathrm{mH}$. The passive filter parameters are shown in Table I. The active filter consists of an IGBT bridge of three SKM50GB123 modules from Semikron. Two sources are connected at the inverter dc side to maintain the capacitor voltages at $\mathrm{V}_{\mathrm{dc}+}=100 \mathrm{~V}$ and $\mathrm{V}_{\mathrm{dc}-}=-100 \mathrm{~V}$. The inverter output includes an LC filter to eliminate voltage ripple. The element values are: $\mathrm{C}_{\mathrm{F}}=50 \mu \mathrm{F}$, $\mathrm{L}_{\mathrm{F}}=0.13 \mathrm{mH}$. The load used consists of a three-phase uncontrolled rectifier. This is an IR 36MT60-type threephase bridge with an inductance of $55 \mathrm{mH}$ in series with a resistance of $16.6 \Omega$ at the dc side.

Two types of tests have been considered: the first one using sinusoidal voltage source and the second one using nonsinusoidal voltage source. In the first test the voltage source generates a balanced sinusoidal waveform, $50 \mathrm{~Hz}$ frequency and phase voltage of $90 \mathrm{~V}$. When the active and passive filters are disconnected, the waveforms shown in Fig. 4a are obtained. The voltage has a 9.6\% THD and the source current a $17.2 \%$ THD.

Table I. Passive elements values
\begin{tabular}{|c|c|c|c|c|c|}
\hline $\mathrm{R}_{5}$ & $\mathrm{~L}_{5}$ & $\mathrm{C}_{5}$ & $\mathrm{R}_{7}$ & $\mathrm{~L}_{7}$ & $\mathrm{C}_{7}$ \\
\hline $2.1 \Omega$ & $13.5 \mathrm{mH}$ & $30 \mu \mathrm{F}$ & $1.1 \Omega$ & $6.75 \mathrm{mH}$ & $30 \mu \mathrm{F}$ \\
\hline
\end{tabular}

Both waveforms are characterized by odd harmonics, except the 3 order and its multiples which are practically null. The voltage rms value is $86.8 \mathrm{~V}$ and the current rms value 7.8 A. The most significant harmonics are the $5^{\text {th }}$ and $7^{\text {th }}$. The active, reactive and apparent powers per phase are: $\mathrm{P}=0.66 \mathrm{~kW}, \mathrm{Q}=0.18 \mathrm{kvar}$ and $\mathrm{S}=0.68 \mathrm{kVA}$. The load has a power factor of 0.96 inductive. The Table III shows the result obtained.

When the passive filter is connected the waveforms shown in Fig. $4 \mathrm{~b}$ are obtained. The voltage THD is $5.1 \%$ and the current THD $7.9 \%$. There is a significative decreasing in the $5^{\text {th }}$ and $7^{\text {th }}$ harmonics rms values, but they are not null because of in the practice the LC branches do not have a zero impedance at tuning frequencies. As a result the voltage rms value is $88.1 \mathrm{~V}$ and the current rms value is $9.6 \mathrm{~A}$.

The active, reactive and apparent powers per phase consumed by the load plus passive filter are: $\mathrm{P}=0.71 \mathrm{~kW}$, $\mathrm{Q}=0.07 \mathrm{kvar}$ and $\mathrm{S}=0.71 \mathrm{kVA}$. The power factor improves until 0.99. There is a slight increase in the active power, which is justified by the resistive effect in the LC branches coils. Reactive power is also reduced because the LC branches is capacitive at the fundamental frequency.

In what follows the passive and active filters are connected. In the first test with active filter, the strategy of source current detection will be applied. This strategy causes an alteration in the location of the uncompensated system poles; it is shown in the second row of Table II. Thus, the poles move away from the imaginary axis and the system stability is strengthened. On the other hand, a stability analysis shows that system is stable for those values of $k>-1.8$.

Table II. Poles situation for different strategies: (1) Without active filter; (2) SCD strategy; (3) LVD strategy; (4) CVD strategy.

\begin{tabular}{|c|c|c|c|c|c|c|}
\cline { 2 - 7 } \multicolumn{1}{c|}{} & $\mathrm{p}_{1}$ & $\mathrm{p}_{2}$ & $\mathrm{p}_{3}$ & $\mathrm{p}_{4}$ & $\mathrm{p}_{5}$ & $\mathrm{p}_{6}$ \\
\hline$(1)$ & $-5.4 \cdot 10^{3}$ & -2.0 & $-185+\mathrm{j} 1.5 \cdot 10^{3}$ & $-185-\mathrm{j} 1.5 \cdot 10^{3}$ & $-185+\mathrm{j} 2.0 \cdot 10^{3}$ & $-185-\mathrm{j} 2.0 \cdot 10^{3}$ \\
\hline$(2)$ & $-1.9 \cdot 10^{4}$ & -10.4 & $-752+\mathrm{j} 1.8 \cdot 10^{3}$ & $-752-\mathrm{j} 1.8 \cdot 10^{3}$ & $-226+\mathrm{j} 1.8 \cdot 10^{3}$ & $-226-\mathrm{j} 1.8 \cdot 10^{3}$ \\
\hline$(3)$ & $-9.1 \cdot 10^{3}$ & -1.12 & $-123+\mathrm{j} 1.5 \cdot 10^{3}$ & $-123-\mathrm{j} 1.5 \cdot 10^{3}$ & $-135+\mathrm{j} 2.1 \cdot 10^{3}$ & $-135-\mathrm{j} 2.1 \cdot 10^{3}$ \\
\hline$(4)$ & $-1.1 \cdot 10^{4}$ & -12.6 & $-987+\mathrm{j} 1.7 \cdot 10^{3}$ & $-987-\mathrm{j} 1.7 \cdot 10^{3}$ & $-190+\mathrm{j} 1.8 \cdot 10^{3}$ & $-190-\mathrm{j} 1.8 \cdot 10^{3}$ \\
\hline
\end{tabular}

On the other hand, from the point of view of eliminating harmonics it is convenient to establish the best $k$ value. The aim is that the system presents a low gain for a given harmonic content. Regardless of the chosen input signal or the output variable, a higher $k$ value becomes smaller the Bode gain. However, the increase of $k$ is not proportional to the decrease of the Bode gain. Fig. 3, reflects this fact more clearly. It shows the gain at a frequency of $250 \mathrm{~Hz}$ ( $5^{\text {th }}$ harmonic) for different $k$ values. A gain of $-30 \mathrm{~dB}$ (in absolute value about 0.03 ) implies that the $5^{\text {th }}$ harmonic drops to a $3 \%$. Therefore, if the supply voltage is distorted a value of $k=5$ would be enough. However, considering that the distortion source is the load current a $k=50$ would be required. In Fig. 3 both situations have been marked. Thus, $k$ proportionality constant is fixed at 50 . This will guarantee the system stability and will reduce the distortion at least until $-30 \mathrm{~dB}$.

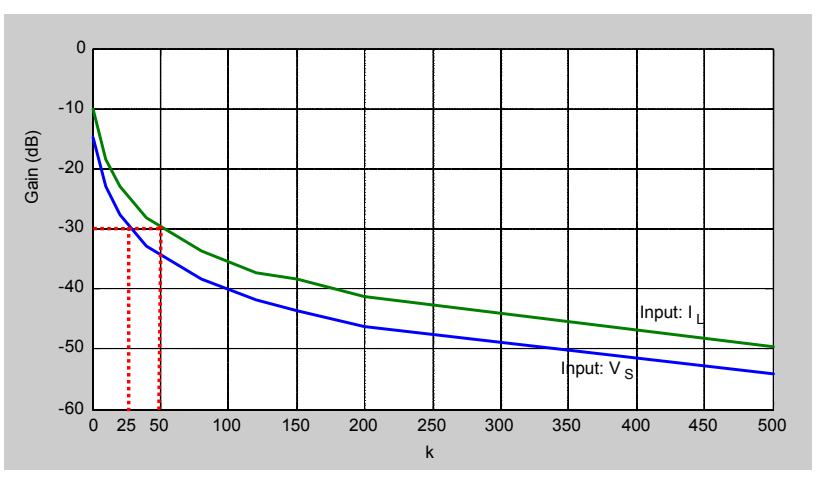

Fig. 3. Bode gain values versus $\mathrm{k}$ at frequency $250 \mathrm{~Hz}$

Fig. $4 \mathrm{c}$ shows the source current and voltage waveforms at the point of common coupling. The voltage THD is $2.0 \%$ 
and current THD is $2.3 \%$, (Table III). There is a significative reduction in the THD with respect to the system without active filter. The voltage and current rms values are $87.6 \mathrm{~V}$ and $87.9 \mathrm{~A}$ respectively. On the other hand, the active, reactive and apparent powers per phase are $\mathrm{P}=0.69 \mathrm{~kW}, \mathrm{Q}=0.03 \mathrm{kvar}$ and $\mathrm{S}=0.70 \mathrm{kVA}$ and the power factor is 0.99 .

In the following test the strategy of load voltage detection is applied to active filter. Taking into account (21), this strategy changes the system matrix and thus the location of the poles. Its behavior depends on the parameter $k_{v}$, which models the instrumentation sensitivity. The value of $k_{v}$ which becomes the unstable system is obtained by simulation. This occurs when $k_{v} \geq 1,198$, since the system would present a pole in the right half plane.

a)

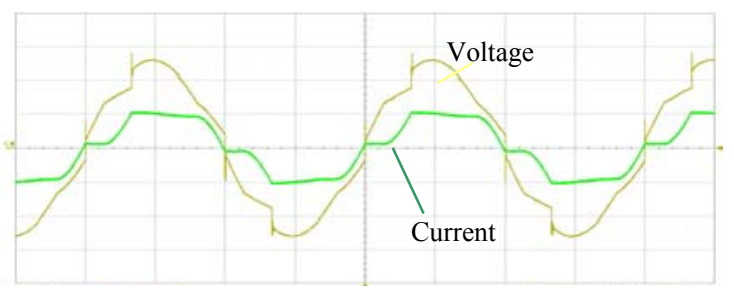

b)

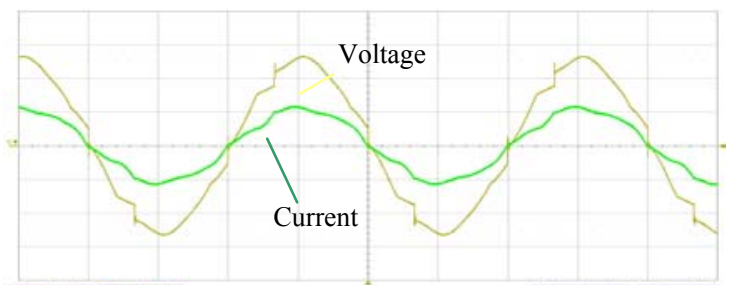

c)

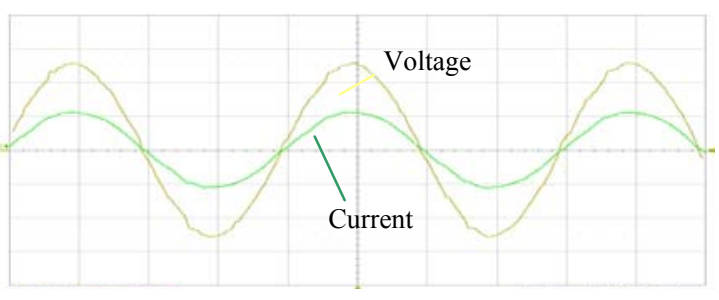

d)

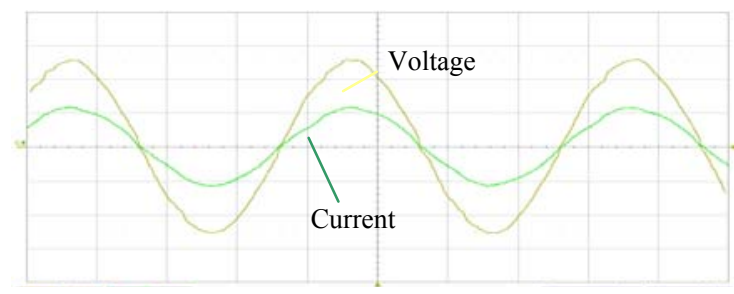

e)

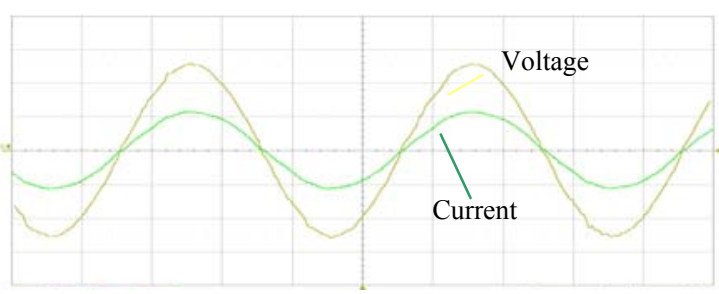

Fig. 4. SAPPF filter behaviour, sinusoidal voltage source: a) without filter; b) with passive filter; c) SCD strategy; d) LVD strategy; e) CVD strategy. Voltage, 48V/div, current, 10/div

From the point of view of eliminating the source current harmonics the aim is that the Bode gain of the system is minimal for a given input signal. This condition is given for $k_{v}=1$, when the current source of the load Norton equivalent is considered as input signal. When the supply voltage is distorted the active filter can even increase the source current harmonic distortion.

Fig. 4d shows the voltage waveform at the point of common coupling and the source current waveform. The voltage THD is $2.1 \%$ and the current THD is $3.5 \%$. This strategy make the source current THD worse. The voltage THD remains practically the same as the strategy of source current detection. The voltage and current rms values are $87.6 \mathrm{~V}$ and $8.0 \mathrm{~A}$, respectively. On the other hand, active, reactive and apparent powers per phase are $\mathrm{P}=0.70 \mathrm{~kW}, \mathrm{Q}=0.04 \mathrm{kvar}$ and $\mathrm{S}=0.70 \mathrm{kVA}$ and the power factor is 0.99 .

Finally, the strategy of current and voltage detection has been applied. Regarding the system stability two parameters must take into account: $k_{v}$ and $k$. In the first analysis, it is considered that $k_{v}=1$, which determines the minimum $k$ value to make the system stable. This occurs for $k>-1.8$. This is the same result obtained with the SCD strategy. When $k_{v}$ is 1.2 , the system is stable if $k>0$. Therefore, with the CVD strategy is achieved to provide greater robustness to the system, making it less sensitive to $k_{v}$ variations. It is evident that for $k_{v}<1$, the stability limit is found for values of $k<-1.8$. From the point of view of stability, if $k_{v}$ has a value close to the unity the system will be stable when $k$ is greater than zero, which will be two design specifications.

From another point of view, when the design specification is fixed to $-30 \mathrm{~dB}$ for the Bode gain at low frequencies and $k_{v}=0.95$ is considered, the $\mathrm{k}$ values must be 29 . This $k$ value ensures a maximum Bode gain of $-30 \mathrm{~dB}$, regardless of the considered distortion source. On the other side, when the supply voltage is slightly distorted, $k$ can be reduced to 12 , having a maximum gain of $-30 \mathrm{~dB}$ at low frequencies. In this case the proportionality constant is fixed at $k=12$.

Fig. 4e shows the voltage and current waveforms. The voltage THD is $1.7 \%$ and the current THD is $2.1 \%$. This strategy reduces the THD corresponding to both signals with respect to the previous strategies. The measured rms values are $87.6 \mathrm{~V}$ for the voltage and 7.9 A for the current. The active, reactive and apparent powers per phase are $\mathrm{P}=0.69 \mathrm{~kW}, \mathrm{Q}=0.03 \mathrm{kvar}$ and $\mathrm{S}=0.70 \mathrm{kVA}$. The power factor is 0.99 .

Table III summarizes the measured data in each experiment. From the point of view of eliminating harmonics, when the supply voltage is sinusoidal the results are similar for the three compensation strategies.

In the second test the SAPPF filter is connected to a distorted supply voltage. The $4500-\mathrm{iL}$ source is programmed to generate a $5^{\text {th }}$ harmonic of $12 \%$ of the fundamental harmonic. Fig. 5 shows the source current and the voltage at the point of common coupling waveforms before and after connecting the active filter. To fix the $k$ values the results obtained in previous analysis are taken into account. Thus, the SCD strategy the $k$ proportionality constant is 50 and using the CVD strategy is $k=29$. 
Table III. Experimental results of the SAPPF filter with sinusoidal source. (1) Without filter; (2) SCD strategy; (3) LVD strategy; (4) CVD strategy

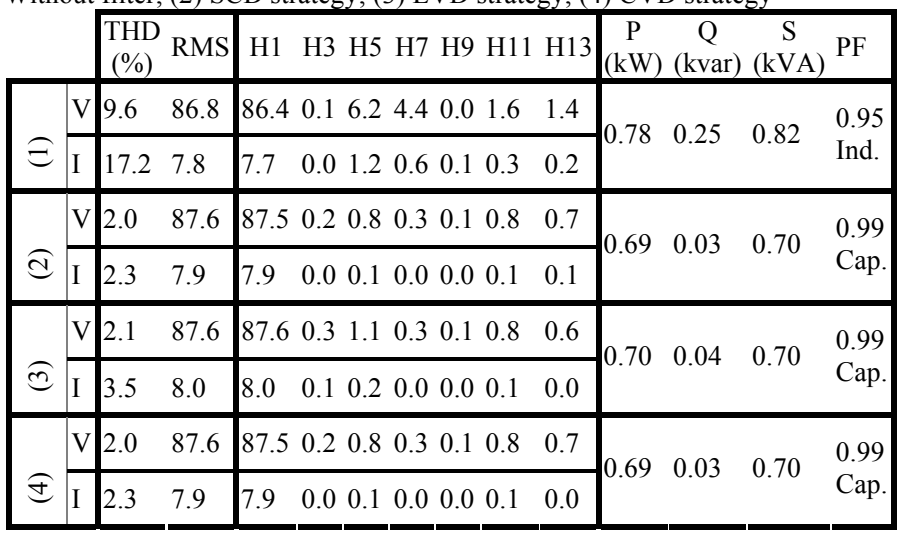

b)
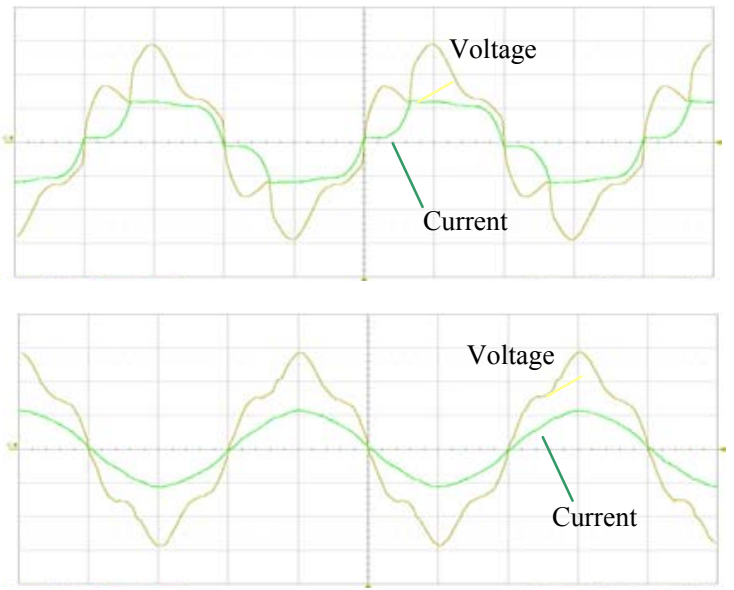

c)

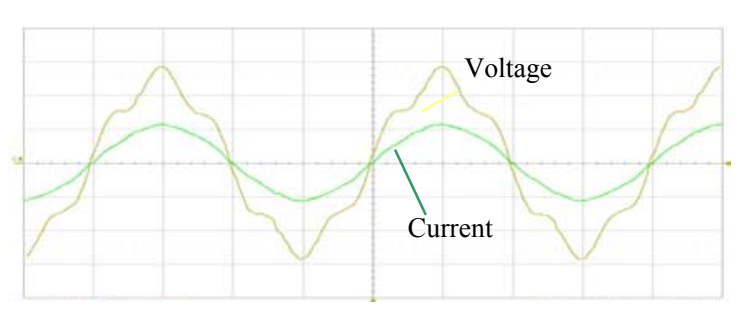

d)

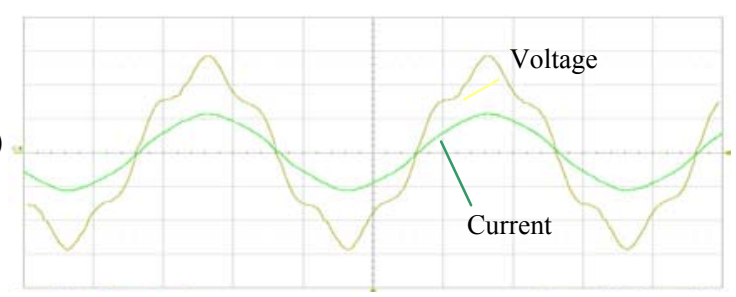

Fig. 5. Voltage an current waveforms of the SAPPF filter with nonsinusoidal source. a) Without filter; b) SCD strategy; c) LVD strategy; d) CVD strategy. Voltage, 48V/div, current, 10/div

Table IV summarizes the most significative measured values: THD, harmonics, power and power factor. The SCD and CVD strategies achieve the source current THD most reduced. In any case, the proposed design methodologies have allowed the source current distortion to be minimized using each control strategy.

\section{Conclusions}

A system dynamic analysis has been carried out by means of the state equations. It has allowed the design guidelines for the APF control to be established. Specifically, using the CVD compensation strategy, the APF voltage is obtained by a combination of a term proportional to the source current harmonics and another term in opposite to the load voltage harmonics. This requires the specification of the proportionality constant in the first term and the sensitivity of the instrumentation in the second term. In this paper, the analysis has allowed the values of these parameters to be chosen from a reduction in harmonic distortion of source current specified by design.

Finally, the proposed methodology has been applied to an experimental SAPPF using each of the three mentioned compensation strategies. The voltage and current waveforms and the measured results in terms of distortion and power before and after compensation have been presented

Table IV. Experimental results of the SAPPF filter with nonsinusoidal source. (1) Without filter; (2) SCD strategy; (3) LVD strategy; (4) CVD strategy

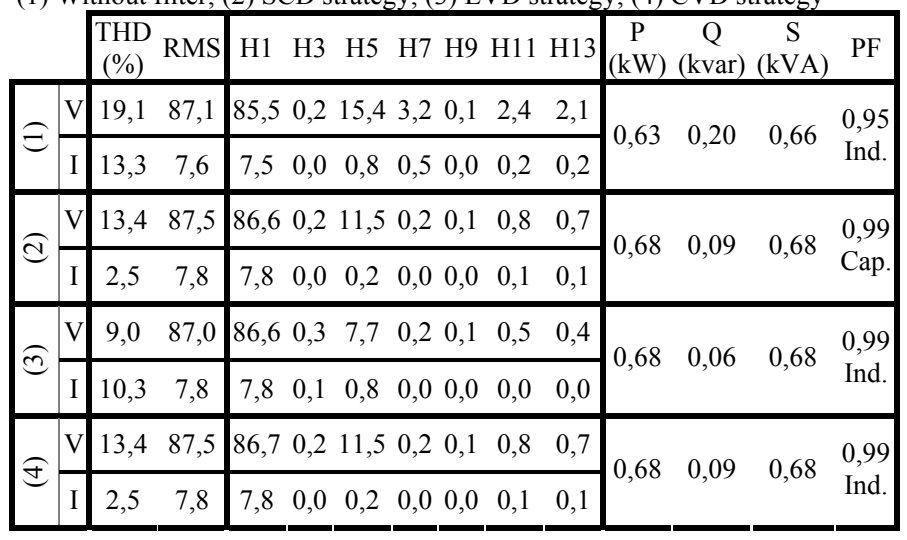

\section{References}

[1] F. Z. Peng and D. J. Adams, "Harmonics sources and filtering approaches," in Proc. Industry Aplications Conference, October 1999, Vol, 1, pp. 448-455

[2] H. Akagi, "Active harmonic filters," Proceedings of the IEEE, Vol 93, Issue 12, Dec. 2005, pp. 2128-2141

[3] Singh, B.; Al-Haddad, K.; Chandra, A. "A review of active filters for power quality improvement" IEEE Trans. on Industrial Electronics, Vol. 46, Issue 5, Oct. 1999, pp. 960 - 971

[4] Herrera, R. S.; Salmerón, P.; Kim, H.; "Instantaneous Reactive Power Theory Applied to Active Power Filter Compensation: Different Approaches, Assessment, and Experimental Results", IEEE Trans. on Industrial Electronics, Vol. 55, Issue 1, Jan. 2008 , pp. 184-196

[5] Lascu, C.; Asiminoaei, L.; Boldea, I.; Blaabjerg, F. "Frequency Response Analysis of Current Controllers for Selective Harmonic Compensation in Active Power Filters", IEEE Trans. on Industrial Electronics, Vol. 56, Issue 2, Feb. 2009, pp. 337-347

[6] Z. Wang, Q. Wang, W. Yao and J. Liu, "A series active power filter adopting hybrid control approach," IEEE Trans. Power Electronics, Vol. 16, No. 3, May 2001, pp. 301-310

[7] F. Z. Peng, H. Akagi, A. Nabae, "A new approach to harmonic compensation in power systems-a combined system of shunt passive and series active filters," IEEE Trans. Industry Applications. Vol, 26, No. 6, Nov/Dec 1990, pp. 983-990

[8] Corasaniti, V. F.; Barbieri, M. B.; Arnera, P. L.; Valla, M. I. "Hybrid Active Filter for Reactive and Harmonics Compensation in a Distribution Network “, IEEE Trans. on Industrial Electronics, Vol. 56, Issue 3, March 2009, pp. 670-677

[9] George, S.; Agarwal, V. "Optimum control of selective and total harmonic distortion in current and voltage under nonsinusoidal conditions," IEEE Trans. on Power Delivery, Vol. 23, Issue 2, April 2008, pp. 937-944

[10] Salmerón, P.; Litrán, S.P.; "Improvement of the Electric Power Quality Using Series Active and Shunt Passive Filters", IEEE Trans. On Power Delivery, Vol. 25, Issue 2, April 2010, pp. 10581067 